\title{
El Acuerdo Trans-Pacífico: oportunidad o riesgo para la salud pública peruana
}

\section{Trans-Pacific Partnership Agreement: an opportunity or a risk for Peruvian public health}

Correspondencia Akram Hernández Vásquez akram.hernandez.v@upch.pe

Recibido: $15 / 03 / 2016$ Aprobado: 13/04/2016

Citar como:

Hernández-Vásquez A, Rebollo W. El Acuerdo Trans-Pacífico: oportunidad o riesgo para la salud pública pervana. Acta Med Peru. 2016;33(1):84-5

\author{
Akram Hernández-Vásquez¹, William Rebollo 2,a \\ 1 Universidad de Buenos Aires. Buenos Aires, Argentina. \\ 2 Instituto de Formación Política para el Liderazgo Democrático. San Salvador, El Salvador. \\ a Abogado
}

\section{Sr. Editor}

Hablar de la propiedad intelectual aplicada al desarrollo de medicamentos hoy es un tema de amplia discusión. Es así, que el desarrollo económico, tecnológico y farmacéutico, especialmente en los países de altos ingresos ha impulsado los procesos de globalización y comercio internacional. De esta forma los países buscan crear bloques de integración económica como estrategia para ampliar sus mercados y generar mayores ingresos con el intercambio de bienes, servicios, capitales y factores productivos. Dentro de este contexto la industria farmacéutica ha buscado involucrarse en temas de negociación internacional que normalmente competen a los Estados como actores internacionales.

Lo anterior genera preocupación debido a que puede llevar a anteponerse intereses privados sobre el interés público [1]. Es conocido que el desarrollo de nuevos productos en la industria farmacéutica conlleva la inversión de grandes cantidades de recursos, por lo tanto, se concede una protección bajo patentes, que permite tener derechos exclusivos de comercialización durante un periodo de tiempo, en el cual se puede obtener un retorno de la inversión más ganancias. Bajo estas patentes se busca incentivar una mayor investigación, desarrollo e innovación (I+D+i) para generar efectos positivos, tales como el acceso a nuevos y mejores medicamentos. Sin embargo, ello también genera efectos negativos como los monopolios farmacéuticos que ocasionan el encarecimiento de precios, lento ingreso de medicamentos genéricos y exclusión en el acceso a productos farmacéuticos para las personas de bajos recursos [2].

Es por ello que la actual firma y proceso de ratificación del Acuerdo de Asociación Transpacífico (Trans-Pacific Partnership Agreement, TPPA) se ve con mucha incertidumbre, pues según la opinión de importantes analistas, tendría la capacidad de incidir negativamente en la salud pública de los países negociantes e interesados, entre ellos, Chile, México y Perú [3]. Las negociaciones del TPPA han sido conducidas bajo un secretismo donde los gobiernos de diferentes países no dieron detalles ni comunicaron una posición completa al respecto [4]. Se puede conceder que hubo buena intención en la negociación aún sin la debida transparencia; sin embargo, es innegable que en la interacción entre oferta y demanda, resulta necesario que se integren algunos elementos de regulación estatal, que protejan las necesidades propias de cada país frente a los poderes económicos. 
La experiencia previa con tratados de este tipo, en diversos países, como con el acuerdo sobre los Aspectos de los Derechos de Propiedad Intelectual relacionados con el Comercio (ADPIC) y sus efectos nocivos sobre el acceso a medicamentos y su consecuente impacto en la salud [5], permiten pensar que efectivamente las negociaciones delTPPA podrían traer también consigo efectos negativos, como los mencionados anteriormente, para los países en desarrollo. Por tanto, es necesario adoptar medidas, tanto en el ámbito privado como en el público, orientadas a prevenir su impacto.

En el ámbito privado, para contrarrestar las distorsiones de mercado que podría producir el TPPA, debiesen implementarse medidas que procuren fomentar la competencia, tales como la generación de sistemas de innovación con diversos actores [6], orientados a aumentar la investigación e innovación en el área de la salud para de esa forma aumentar la oferta de medicamentos y con ello generar una regulación de precios en base a la competencia. En el sector público, por otra parte, podrían aplicarse salvaguardas amparadas en la declaración de Doha dada en la cuarta conferencia mundial de la Organización Mundial del Comercio, orientadas a proteger la salud pública y el acceso a medicamentos [7], y además implementarse sistemas nacionales de cobertura universal para garantizar el acceso a medicamentos a la población, produciendo con ello efectos regulatorios de precios en el mercado.

Por tanto, la protección de la salud no debe ni puede estar solamente librada a la voluntad de los individuos o a las fuerzas del mercado sino que debe involucrar cada vez a más actores y especialmente a aquellos de la sociedad civil que finalmente son los más impactados por las decisiones que en materia de políticas públicas son tomadas.

En conclusión, el futuro nos exige una visión más humana en los procesos de comercio y tratados internacionales, aplicando además en ellos un enfoque de derechos en función de los intereses de la población, para lograr de esa forma una disminución progresiva de las grandes desigualdades que afectan hoy en día a la humanidad; en ese sentido, la negociación y firma delTPPA nos brindan la oportunidad de repensar la forma de la generación de las políticas públicas orientándolas a la consecución del bien común y garantizando el acceso efectivo a los servicios de salud para aquellos que lo necesitan.

Fuente de financiamiento: autofinanciado.

Conflictos de interés: los autores declaran no tener conflictos de interés con la publicación de este artículo.

\section{REFERENCIAS BIBLIOGRÁFICAS}

1. Paina $L$, Peters $D H$. Understanding pathways for scaling up health services through the lens of complex adaptive systems. Health policy and planning. 2012;27(5):365-73.

2. Alcorn T. TPP: trade-offs for health behind closed doors. Lancet. 2016;387(10022):929-30.

3. Stiglitz JE. Don't trade away our health [Internet]. NewYorkTimes Company; 2016. Published January 30, 2015. Accessed 10, 2015. Disponible en: http://www.nytimes.com/2015/01/31/opinion/donttrade-away-our-health.html?_r=0

4. Kapczynski A. The Trans-Pacific partnership--is it bad for your health? N Engl J Med. 2015;373(3):201-3.

5. Llamoza J. Tratados comerciales y acceso a medicamentos en el Perú. Rev Peru Med Exp Salud Publica. 2009;26(4):530-6.

6. Padilla R, Gaudin Y, Rodríguez P. Sistemas de innovación. In: Padilla Pérez R, ed. Sistemas de innovación en Centroamérica: fortalecimiento a través de la integración regional. Santiago de Chile: Comisión Económica para América Latina y el Caribe (CEPAL); 2013. p. 27-49.

7. Zapatero Miguel P. Legal and policy foundations for global generic competition: Promoting affordable drug pricing in developing societies. Global Public Health. 2015;10(8):901-16.

\title{
Ahora puede enviar sus artículos para Acta Médica Peruana en nuestro Open Journal System:
}

\author{
www.amp.cmp.org.pe
}

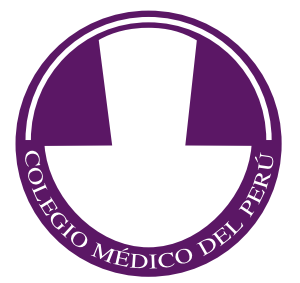

